\title{
RESENHA
}

\section{Alexander von Humboldt e a invenção da natureza, por Andrea Wulf}

WULF, Andrea. A invenção da Natureza: a vida e as descobertas de Alexander von Humboldt. São Paulo: Planeta, 2016.

\author{
Juliana Capra Maia \\ Universidade de Brasília, Brasil \\ Dittps://orcid.org/0000-0002-5994-4028 \\ capra.juliana@gmail.com
}

O livro A invenção da Natureza: a vida e as descobertas de Alexander von Humboldt, da autoria de Andrea Wulf é, a um só tempo, biografia de Humboldt, história da ciência do século XIX e análise de uma ampla gama de fontes primárias, tais como jornais, revistas, cartas, diários e livros publicados pelo próprio Humboldt. Considerado um best seller, o trabalho de Wulf recebeu diversos prêmios internacionais por suas qualidades literárias e por sua contribuição à ciência.

Conta-nos Andrea Wulf que Alexander von Humboldt nasceu em 1769 no seio de uma família prussiana aristocrática e que recebeu uma educação esmerada. Fascinado com as diferentes formas de vida, 
ainda criança, Humboldt aventurava-se ao ar livre para coletar e desenhar plantas, pedras e animais. Era comum voltar para casa com os bolsos cheios de insetos e plantas, razão pela qual a sua família o apelidara de "pequeno boticário".

Pertencente a uma família politicamente influente e herdeiro de uma grande fortuna, Humboldt, que era mineralogista e naturalista, viajou para lugares até então impenetráveis aos europeus médios em busca de espécimes, mas, principalmente, em busca de leis naturais. Dotado de uma memória privilegiadíssima, Humboldt conseguia fazer comparações entre seres, objetos e fenômenos separados entre si por milhares de quilômetros: espécimes botânicos encontrados nos Alpes Suíços (Europa), na Cordilheira dos Andes (América do Sul) ou nas Montanhas Altai (Ásia), por exemplo. Esse talento lhe permitiu fundir observação empírica (mandamento iluminista) e subjetividade (mandamento romântico), de modo que seus livros eram famosos pela abundância de dados e pela boa prosa intimista. Desse modo, Humboldt aproximou poetas e naturalistas na revolucionária ideia de que a natureza seria uma complexa teia de vida, cheia de interconexões. Tal ideia, pressuposto de toda a ecologia, é atualmente tomada como truísmo: motivo pelo qual, especula Wulf, o nome de Humboldt tenha sido praticamente esquecido na ciência ocidental.

No final do século XVIII as viagens internacionais não eram empreendimentos banais para civis. Além da imprevisibilidade do transporte marítimo, a resistência das monarquias europeias à Revolução Francesa e as subsequentes guerras napoleônicas demandaram navios e fecharam as fronteiras dos países europeus e de suas respectivas colônias para estrangeiros. Em 1799, articulando-se com integrantes influentes da corte espanhola, Humboldt conseguiu autorização especial de Carlos IV para adentrar em seus territórios na América Latina 
e nas Filipinas. As únicas condições seriam as de que caberia a Humboldt financiar a expedição e, como retribuição à autorização concedida, despachar exemplares da fauna e da flora das colônias espanholas para os jardins reais em Madri.

No início de junho de 1799, Humboldt embarcou para a América a bordo da fragata Pizzarro, na companhia do botânico francês Aimé Bonpland, de 42 instrumentos de medição e de orientação cuidadosamente embalados (bússolas, balanças, telescópios, microscópios, termômetros), além de um sem-número de ferramentas. Em 16 de julho de 1799, isto é, cerca de 40 dias depois de terem deixado La Coruña/Espanha, aportaram todos Nova Andaluzia, província da Capitania Geral da Venezuela. Uma vez em terra, rumaram para a cidade de Cunamá, onde ficaram hospedados por algumas semanas até partirem para Caracas. A permanência de Humboldt e de Bonpland na América, em expedições científicas, perdurou por mais de 5 anos.

Partindo de Caracas, Humboldt e Bonpland atravessaram a inóspita planície dos Llanos para alcançar o Rio Orinoco, navegaram o rio Cassiquiare, canal que une as Bacias dos Rios Amazonas e Orinoco, confirmando o relato de um jesuíta que, já no século XVI, afirmava que as duas gigantescas bacias hidrográficas se encontravam. Mais tarde, Humboldt e Bonpland percorreram a Cordilheira dos Andes, escalaram ativos vulcões equatorianos (Pichincha, Chimborazo e Cotopaxi) e visitaram os territórios que hoje denominamos Texas, México e Cuba. Na América Central, tiveram acesso a relíquias dos Impérios Maia e Asteca, a partir das quais Humboldt concluiu que os ameríndios eram povos sofisticados, um julgamento bastante diverso daquele majoritário entre os europeus letrados da primeira metade do século XIX.

As experiências de Humboldt durante as suas incursões na Amé- 
rica Latina lhe converteram num convicto abolicionista. Em Cunamá, a casa que alugara ficava bem em frente ao mercado de escravos. Por isso, Humboldt várias vezes testemunhou jovens africanos seminus, recém-chegados ao Novo Mundo, tendo de exibir os corpos e os dentes para compradores, como fossem animais em leilões. Humboldt considerou esse tratamento inaceitável, até porque, destoando da maioria dos europeus de sua época (inclusive de respeitados intelectuais como Buffon), enxergava os negro-africanos como iguais. Para Humboldt, nem os negros, nem os ameríndios eram inferiores aos homens brancos, motivo pelo qual a escravidão seria um instituto imoral.

Também foi na América Latina que Humboldt associou agricultura monocultora e degradação ambiental. Visitou regiões bastante férteis, tais como o Vale do Aragua. Com os seus arredores intensamente cultivados, os níveis da água no Lago Valência vinham decaindo rapidamente. Após investigar as causas do fenômeno, Humboldt concluiu que o desmatamento das florestas adjacentes ao Lago e a transposição de cursos d'água para irrigação das lavouras vinham provocando a redução dos níveis do corpo hídrico. Essa correlação entre desmatamento e mudanças climáticas locais ficou conhecida como "teoria do dessecamento" e por todo lugar impactou intelectuais preocupados com o tratamento dispensado à natureza. Observe-se que essa teoria vem sendo aceita pelos críticos ambientais luso-brasileiros desde os tempos do Brasil Colônia (PÁDUA, 2002; FRANCO, DRUMMOND, 2009).

Finalmente, também na América Latina, Humboldt associou colonialismo e devastação ambiental. Em Cuba, os europeus haviam substituído a floresta tropical por grandes fazendas de açúcar; nos arredores de Cumaná, por açúcar e índigo. Humboldt observou que, além do empobrecimento do solo e do ressecamento dos cursos hídricos, 
esse modelo econômico gerava dependência, pobreza e infelicidade para as populações locais. Em Cuba ou em Cumaná, apesar da fertilidade da terra, os colonos morreriam de fome caso não conseguissem importar alimentos produzidos alhures. Humboldt também encontrou características similares na Cidade do México e no Vale do Rio Apure.

Em outras palavras, segundo o autor, o colonialismo voltado à exportação de produtos primários vinha provocando degradação da natureza e empobrecimento das populações locais onde quer que fosse implantado. Além disso, a injusta distribuição de terras, a violência contra grupos tribais, as péssimas condições de trabalho a que eram submetidos os povos indígenas e as iníquas imposições metropolitanas fizeram de Humboldt um simpatizante da Revolução Americana e ferrenho opositor do colonialismo.

Como resultado da expedição à América, Humboldt publicou diversos livros, o primeiro intitulado Ensaio sobre a geografia das plantas. Esse trabalho - o primeiro livro sobre ecologia - incluía o desenho da sua Naturgemälde, elaborado aos pés do vulcão equatoriano Chimborazo. A ilustração apresentava o Chimborazo a partir de um corte transversal: plantas, do sopé à linha da neve, variavam em distribuição, quantidade e morfologia, em função de zonas climáticas, altitude e latitude. Portanto, Humboldt agrupou os vegetais por zonas e regiões geográficas, ao invés de agrupá-los em unidades taxonômicas, como era a praxe na botânica praticada até então.

Foi assim que o Ensaio sobre a geografia das plantas, além de inaugurar a biogeografia, apresentou ao mundo uma invisível teia de vida. A natureza era um reflexo do todo e só poderia ser adequadamente compreendida se os cientistas olhassem de maneira ampla para fauna, flora e estratos geológicos. Essa compreensão sobre a natureza como totalidade orgânica também aparece nos outros trabalhos do au- 
tor: Quadros da natureza, Vistas das cordilheiras e monumentos dos povos indígenas da América, Ensaio Político sobre o Reino da Nova Espanha, Ensaio Político sobre a Ilha de Cuba, Narrativa Pessoal, Ensaio geognóstico sobre a sobreposição de rochas, As linhas isotermas e a distribuição de calor no globo.

Em junho de 1829, quase sexagenário, Humboldt partiu para mais uma expedição. Agora, a ciência o levava ao oriente, no ponto em que Rússia, China e Mongólia se encontravam. As montanhas Altai - o mais perto que Humboldt conseguiu chegar da Ásia Central - lhe serviram como referencial de comparação botânico, geológico e zoológico em relação à Cordilheira dos Andes. A viagem, mais de 16 mil km percorridos em carruagens, durou menos de menos de 6 meses. Foi financiada pelo Czar Nicolau I, interessado nos conhecimentos geológicos de Humboldt e no melhor aproveitamento dos recursos minerais russos.

O investimento do monarca foi bem remunerado. Humboldt notou características geológicas semelhantes entre as minas de ouro e platina dos Urais com aquelas que, muitos anos antes, ele havia inspecionado na América Latina. Por isso, apesar de nunca terem sido encontrado diamantes fora dos trópicos, Humboldt estava certo de que o território russo era cheio deles. Instigado por Humboldt, o Conde Polier dirigiuse às minas de sua esposa, em Ecaterimburgo, e instruiu os mineiros a procurarem por diamantes. Pouco depois, foi encontrado o primeiro diamante dos Urais.

Para além da descoberta dos diamantes, a expedição russa também resultou na publicação de Fragmentos de Geologia e de Climatologia Asiáticas e, mais tarde, na publicação de Cosmos: Projeto de uma Descrição Física do Mundo, a obra magna na qual Humboldt se propôs a tratar de tudo o que existisse entre o céu e a Terra. 
Humboldt começou a escrever Cosmos aos 65 anos de idade. Além dos próprios, se valeu de dados científicos produzidos por seus correspondentes em todo o mundo. Recebeu, de seus colaboradores, mapas produzidos por geólogos, coordenadas calculadas por astrônomos, listas de plantas (dos mais longínquos rincões) elaboradas por botânicos e gravuras de fósseis gregos, entre várias outras fontes. Considerando-o um empreendimento impossível, o autor levou mais de uma década para escrevê-lo e finalmente publicá-lo. Em Cosmos, que foi lido por intelectuais, estudantes, religiosos, políticos e artistas de vários países, Humboldt mais uma vez expôs o seu entendimento de que a Terra formava uma maravilhosa rede de vida. O livro foi um sucesso imediato de vendas, superando, inclusive, a façanha comercial de Fausto, obra-prima de Goethe.

Andrea Wulf esclarece que, até então, os escritos e os métodos de Humboldt haviam impactado bastante os intelectuais europeus (entre eles, Charles Darwin), mas muito pouco os estadunidenses. Cosmos mudaria radicalmente esse panorama. Edgar Allan Poe, Ralph Waldo Emerson e Walt Whitman o leram e nele buscaram inspiração para a sua obra literária. Mais tarde, Humboldt também arrebataria Henry David Thoureau, George Perkins Marsh e John Muir, precursores da preocupação com a natureza em terras estadunidenses. Isso permitiu que o conceito da natureza como rede de vida se enraizasse profundamente no pensamento ocidental, tornando-se verdadeiro pressuposto da moderna ecologia.

Alexander von Humboldt era um ator central do mundo intelectual ocidental no século XIX: frequentava salões, correspondia-se com pensadores de todos os cantos - inclusive, conforme Pádua (2009), com José Bonifácio de Andrada e Silva - e apoiava jovens cientistas. Mas além de influenciar cientistas, artistas, romancistas e poetas, 
Humboldt era próximo ao poder e também impactou políticos e líderes revolucionários.

Em 1806, foi nomeado tesoureiro de Frederico Guilherme III, rei da Prússia, uma distinção honorífica, generosamente remunerada e que apenas lhe demandava estar por perto, à disposição do soberano para lhe animar a corte. Ali, a sua influência política resumia-se à tentativa de criar uma certa "atmosfera” favorável a ideias progressistas, já que o Estado prussiano era monárquico, militarizado, antiliberal e antidemocrático: tudo aquilo a que Humboldt se opunha. Mas o autor não podia se dar ao luxo de virar as costas ao seu rei. Nessa época, Humboldt já estava financeiramente dependente da pensão que recebia como tesoureiro da corte, visto que praticamente toda a sua fortuna havia sido despendida na expedição à América Latina e nas publicações dela resultantes.

Nos muitos salões que frequentava, Humboldt conheceu e inspirou o revolucionário sul-americano Simón Bolivar. Na época, 1804, Bolívar era um dândi da elite criolla venezuelana, que viajava pela Europa em jogatinas e bebedeiras de modo a se consolar pelo falecimento da esposa. Bolívar se apoiou nas críticas de Humboldt ao colonialismo para combater o jugo espanhol sobre a sua terra natal. Wulf argumenta que as imagens, metáforas e alegorias da natureza utilizadas pelo naturalista prussiano tornaram-se o cerne do discurso bolivariano pela liberdade. Bolívar também se informou sobre as terras que pretendia libertar por meio dos escritos e mapas elaborados por Humboldt: afinal, apesar de venezuelano, ele ainda não conhecia boa parte do continente.

O "homem mais famoso do mundo depois de Napoleão" - apelido que Humboldt recebeu de seus contemporâneos - também teria se encontrado e se correspondido com Thomas Jefferson e com James Ma- 
dison. Valiosas informações acerca da quantidade e da natureza das ocupações humanas no Texas, fornecidas aos líderes americanos por Alexander von Humboldt, teriam sido utilizadas nas guerras contra o México em favor da expansão do território estadunidense.

Wulf conclui que a memória de Humboldt, nos países anglófilos, esmaeceu devido ao caráter holístico dos seus escritos, característica que saiu de moda à medida que as diversas ciências prezavam cada vez mais pela especialização, pela independência dos seus respectivos objetos e campos de estudo. Além disso, o sentimento antigermânico aflorado na Inglaterra e nos Estados Unidos após a Primeira Grande Guerra, argumenta Wulf, teria sido outra razão central para que Humboldt acabasse esquecido. Afinal, nessa época, livros alemães foram incendiados ou excluídos de bibliotecas públicas, ruas foram renomeadas e mesmo a família real britânica alterou o seu patronímico de “Saxe-Coburgo-Gotha” para “Windsor”. Não é estranho, portanto, que o protagonismo de Alexander von Humboldt na história da ciência tenha sido apagado.

Os dilemas ambientais enfrentados pela humanidade desde o final do século XX, não obstante, têm revalorizado as abordagens interdisciplinares. Por isso, há espaço para que Humboldt torne a ocupar a sua merecida posição entre os pais-fundadores da ciência ocidental.

\section{Referências}

FRANCO, José Luiz de Andrade; DRUMMOND, José Augusto. Proteção à natureza e identidade nacional no Brasil, anos 1920 - 1940. Rio de Janeiro, Editora Fiocruz, 2009. 
PÁDUA, José Augusto. Um sopro de destruição: pensamento político e crítica ambiental no Brasil escravista (1786-1888). Rio de Janeiro: Jorge Zahar Ed., 2002.

WULF, Andrea. A invenção da Natureza: a vida e as descobertas de Alexander von Humboldt. São Paulo: Planeta, 2016. 
Recebido para publicação em 07/03/2019.

Aceito em 19/07/2019.

Revista de Ciências Sociais. Fortaleza, v. 51, n. 1, mar./jun., 2020, p. 407-417. 